\title{
Construction and in vitro characterisation of aroA defective (aroA $\Delta$ ) mutant Salmonella Infantis
}

\author{
İnci Başak Müştak ${ }^{1} \cdot$ Hakan Yardımcı ${ }^{1}$
}

Received: 21 January 2019 / Revised: 24 May 2019 / Accepted: 14 June 2019 / Published online: 25 June 2019

○) Springer-Verlag GmbH Germany, part of Springer Nature 2019

\begin{abstract}
Poultry vaccine programs are important for control of Salmonella infections. Although there are vaccines for Salmonella Enteritidis, Salmonella Typhimurium and Salmonella Typhi, there are no vaccines for Salmonella Infantis which has an increased rate in the world. In this study, it was aimed to generate aroA gene deleted mutant bacteria for the constitution of $S$. Infantis vaccine prototype and the in vitro characterisation of this bacterium. $S$. Infantis auxotrophic mutant which has a block at any step of chorismate pathway has been constituted for the first time in the world and it was determined that this bacterium gets susceptibility against some antibiotics and antimicrobial substances. It was also observed that the adhesion and invasion rate of mutant strain tenfold decreased in comparison with the field strain in cell culture assay. It is understood from the in vitro evaluation of this mutant strain that it can be used as a vaccine candidate in further vaccine development studies.
\end{abstract}

Keywords aroA gene $\cdot$ Auxotrophic mutant $\cdot$ Recombinant vaccine $\cdot$ Salmonella Infantis

\section{Introduction}

Salmonella infections, which cause serious losses in the poultry industry, have been seen as a major problem since the 1900s. Although Salmonella Enteritidis and Salmonella Typhimurium are the most isolated serotypes in poultry, Salmonella Heidelberg, Salmonella Kentucky and Salmonella Infantis serotypes are also frequently seen. These serovars are capable of producing a variety of infections both in humans and in animals (Barrow et al. 2010).

According to the worldwide prevalence of Salmonella serotypes observed in humans and various foodstuffs, an epidemiological link has been established between poultry products and Salmonellosis seen in humans, and, it has been shown that the serotypes isolated from poultry meat products (chicken and turkey meat) are similar to the serotypes

Communicated by Erko Stackebrandt.

İnci Başak Müştak

inciibasak@hotmail.com

Hakan Yardımcı

yardimci.h@gmail.com

1 Department of Microbiology, Faculty of Veterinary Medicine, Ankara University, Şehit Ömer Halisdemir Bulv. Dışkapı, 06110 Ankara, Turkey seen in humans. In Europe, the frequency of Salmonella serotypes that cause infections in humans has been reported and, in some cases, these serotypes have been similar to the serotypes observed in poultry. According to the report in Europe in 2013, there is an increase in the proportion of Salmonella serotypes that cause infections in humans due to consumption of poultry meat (chicken and turkey). Among these: Salmonella Infantis, Salmonella Stanley and Salmonella Kentucky were found to be the most frequently isolated serotypes. The proportion of $S$. Infantis causing infections in humans in Europe between 2011 and 2013, particularly broiler chickens and broiler chickens' meat origin, increased by $26.5 \%$ (Antunes et al. 2016).

From 2001 onwards in Europe and especially in Germany, $S$. Infantis, which is not host dependent, is the top serotype among $S$. enterica serotypes isolated from human cases. Since 970 s this serotype has been increasingly reported in Argentina, Australia, Brazil, Netherlands, Finland, Canada, Hungary, Japan, New Zealand and Russia. Animals and especially chickens are reported as the most important reservoir of this $S$. Infantis Salmonellosis in humans (Miller et al. 2010).

Since the early 1980s it has been known that virulence of auxotrophic Salmonella mutants, lacking aromatic amino acids, is low for animals (Hoiseth and Stocker 1981). Since then mutations in genes responsible for the biosynthesis 
of aromatic amino acids in different Salmonella serotypes have been used to reduce virulence. It has been determined that aroA and aroD mutants of Salmonella enterica serovar Typhi are successful as a vaccine against typhoid in humans (Tacket et al. 1997; Tacket et al. 2000). Similar mutations have been used to generate avirulent strains for immunization of different farm animals (Robertsson et al. 1983; Cooper et al. 1994b; Everest et al. 1999). Aro mutants were found to be avirulent even in gnotobiotic mice known to be quite sensitive. The decrease in virulence seen in aroA mutants is mainly explained by the lack of production of aromatic amino acids and aromatic metabolites such as phenylanine, tyrosine and tryptophan.

The aroA is the gene located in the first step of the aromatic amino acid biosynthesis pathway and is required for the synthesis of paraaminobenzoic acid (PABA) and is a part of the shikimate pathway which is directly related to the glycolysis required for aromatic amino acid synthesis (Sebkova et al. 2008; Felgner et al. 2016).

In bacteria, the synthesis of aromatic amino acid starts in common. In this biochemical pathway, degradation of the pre-chorismate pathway by mutation of aroA, the gene responsible for 5-enolpyruvylshikimate 3-phosphatase synthesis from seven enzymatic reactions, is used as a common strategy in many attenuation studies (McArthur et al. 2003).

The aroA gene mutation has been reported as a potential live vaccine candidate in animals for the past 30 years with success for many Gram-negative bacteria, especially respiratory pathogens such as Salmonella sp., Bordetella pertusis, Pasteurella multocida and Mannheimia haemolytica (Garside et al. 2002).

In this study, it was aimed to develop a vaccine candidate against $S$. Infantis frequently isolated from poultry by the previously used aroA gene mutation technique against $S$. Enteritidis and $S$. Typhimurium, and to characterise and compare the mutant strain generated with the wild-type strain under in vitro conditions.

\section{Materials and methods}

\section{Strains}

Salmonella Infantis strains focused on in this study were obtained from departmental archive of Department of Microbiology, Faculty of Veterinary Medicine, Ankara University. The strains were isolated from poultry flocks (base material and dust) as described in ISO 6579 and serotyped according to Kauffmann-White-Le Minor scheme (Grimont and Weill 2007). Among these strains, S. Infantis strains with the most observed ribo-pattern type (ribotyping banding patterns) in the ribotyping library were used. Ribotyping is a molecular technique used for the identification of bacteria by cutting the rRNA at specific sites, resulting in pieces of rRNA of different lengths unique for each strain. Ribotyping was performed by RiboPrinter System (DuPont, USA) based on the analysis of the band profiles resulting from cutting the rRNA operon with the $P v u I I$ restriction enzyme (Thermo Scientific, USA).

\section{Bacterial genomic DNA extraction}

One or two colonies (depending on size of the colony) from cultured $S$. Infantis strains were harvested in Eppendorf tubes containing $200 \mu \mathrm{l}$ of nuclease-free buffer and were centrifuged at $5000 \times g$ for $10 \mathrm{~min}$. The supernatant was discarded and genomic DNA (gDNA) extraction from pellet was performed with the GeneJet Genomic DNA Purification kit (Thermo Scientific, USA) according to the manufacturer's instructions.

\section{Construction of cloning vector for aroA gene deletion}

The aro $A$ gene including approximately 200 nucleotides upand downstream flanking sequences were amplified from gDNA of selected $S$. Infantis strains with conventional PCR using the primers designed (Table 1) based on the sequence of $S$. Infantis isolated from healthy broilers in Hungary and UK (GenBank Acc. Number: LN649235). Approximately $2000 \mathrm{bp}$ genomic region including aroA gene was amplified using Phusion High-Fidelity DNA Polymerase (Thermo Scientific, USA). The PCR product was then purified with the QIAquick PCR Purification kit (Qiagen, Germany) and final product was inserted into the pJET1.2/blunt cloning vector with the CloneJet PCR Cloning kit (Thermo Scientific, USA) according to the manufacturer's instructions. The resulting construct was named as pJETaroA (approximately $5000 \mathrm{bp}$ in size). The entire aroA-coding region was deleted from pJETaroA bt digestion with SalI restriction endonuclease (Thermo Scientific, USA) and the resulting large fragment (4000 bp) was gel-extracted (QIAquick Gel Extraction kit, Qiagen, USA) and blunt-ended with T4 DNA polymerase (Thermo Scientific, USA). The plasmid generated was named as pJETaroA- $\Delta$. As a marker gene (for tracking mutant $S$. Infantis) GFP coding gene was inserted into pJETaroA- $\Delta$. In order to do this, pGFPuv vector

Table 1 Primers used in this study

\begin{tabular}{|c|c|c|}
\hline Name & Primer sequence $\left(5^{\prime} \rightarrow 3^{\prime}\right)$ (start nt) & Purpose of use \\
\hline $\operatorname{aroA}-\mathrm{F}$ & tctttccggtctggtgtt (311) & Gene amplification \\
\hline $\operatorname{aroA}-\mathrm{R}$ & gacgtttggtgtatttgctt (2361) & \\
\hline MaroA-F & ctccttaatatccctccaac (551) & Proof of aroA deletion \\
\hline MaroA-R & atcaccttcacctctcc (1887) & \\
\hline
\end{tabular}


(Clontech, USA) was digested with EcoRI and $P v u I I$ restriction enzymes (Thermo Scientific, USA) and the resulting small fragment (approximately $950 \mathrm{bp}$ in length) was gelextracted as described before and inserted into pJETaroA $(-)$ using the enzyme T4 DNA Ligase (Thermo Scientific, USA) (Fig. 1a, b). The positive clones green fluorescing under UVlight were selected from agar surface. The resulting cloning vector was finally confirmed by nucleotide sequencing bidirectionally using the first amplification primers and the final construct named pJETaroA- $\Delta / \mathrm{GFP}$.

\section{Production of aroA defective bacteria}

Confirmed pJETaroA- $\Delta$ /GFP plasmid was first linearized with NotI restriction enzyme (Thermo Scientific, USA). Subsequently, the plasmid was transformed to $S$. Infantis strain, which is selected in the appropriate replication period $\left(\mathrm{OD}_{600}\right.$ 0.4-0.6), according to the method of Sambrook and Russell (2001) (Fig. 1c). Recombinant bacterium was subjected to PCR analysis, plasmid elimination, sequence analysis and Western blot for further analysis. PCR analysis was performed with confirmatory primers (MaroA) in order to amplify approximately $1400 \mathrm{bp}$ of the gDNA region, which included inserted reporter GFP gene surrounded by the phosphoserine aminotransferase (PSAT) gene located in front of the deleted aroA gene.

The generated aroA-defective $S$. Infantis strain, apart from the wild strain from which it originated, had the ampicillin-resistance gene from the plasmid transferred. Thus, the plasmid was eliminated using the method described by Carlton and Brown (1981). According to this curing technique, the strains were incubated at $5-7{ }^{\circ} \mathrm{C}$ above the optimal growth temperature. The culture was re-incubated at the elevated temperature until it became ampicillin-sensitive. Curing of the plasmid was confirmed by culturing the strains on Luria-Bertani agar media with ampicillin. Confirmation of the GFP gene in aroA-defective $S$. Infantis strain's gDNA after plasmid removal was performed by PCR analysis using MaroA-primers as before. Then, plasmid-eliminated mutant bacteria was sequenced. The Western Blot (WB) analysis was performed according to the method of Sambrook and Russel (2001) to reveal the expression of the GFP gene in the recombinant bacteria using anti-GFP-tag polyclonal antibody (Thermo Scientific, USA).

\section{Characterisation of recombinant bacteria}

To show the auxotrophy, $\operatorname{aro} A \Delta S$. Infantis and wild-type $S$. Infantis strains were cultured on M9 minimal medium with and without aromatic amino acids (phenylalanine, tryptophan and tyrosine) which were prepared according to the method of Sambrook and Russel (2001) and incubated at $37{ }^{\circ} \mathrm{C}$ for $18-24 \mathrm{~h}$.
Generated $a r o A$-defective $S$. Infantis ( $\operatorname{rro} A \Delta S$. Infantis) strain was compared to $S$. Infantis wild-type strains, $S$. Enteritidis wild-type strains and $S$. Typhimurium wild-type strains in terms of some phenotypic and genotypic methods such as $\mathrm{H}_{2} \mathrm{~S}$ formation, colony morphology, several biochemical tests, reproduction profiles, antibiotic resistance profiles and antimicrobial susceptibilities. For these tests, MacConkey, XLD, Nutrient, TSI and O/F media were used. Fully automated biological screening device (BioScreen C MBR, Finland) was employed to determine the growth curve and motility test was performed based on the method of Tittsler and Sandholzer (1936).

For antibiotic resistance profiling, Mueller-Hinton agar cultures were used and antibiotics indicated in Table 2 were tested according to the European Committee on Antimicrobial Susceptibility Testing (EUCAST) criteria by disk diffusion method (EUCAST 2014). EDTA susceptibility test was conducted to investigate the properties of bacteria against antimicrobial agents. For this reason, the MIC test was performed.

Pulsed Field Gel Electrophoresis (PFGE) was also used for genotyping. Recombinant $S$. Infantis strains with and without plasmid elimination, $S$. Infantis wild-type strain, $S$. Enteritidis and $S$. Typhimurium strain were used for the test. Each strain was cultured on Nutrient agar media and incubated for $18-24 \mathrm{~h}$ at $37^{\circ} \mathrm{C}$. Gel electrophoresis was prepared according to the Centers for Disease Control and Prevention (CDC, USA) protocol (CDC 2018).

\section{Whole genome sequencing}

Library preparation was done using TruSeq Nano DNA Low Throughput Library Prep Kit (Illumina, San Diego, CA, USA). Whole genome sequencing was performed as pairedend $(150 \mathrm{bp} \times 2)$ sequencing on Illumina HiSeq 2500 platform (Illumina, San Diego, CA, USA). The aim of coverage was $>30 \times$. FastQ file was uploaded to the Galaxy platform (https://usegalaxy.org/) and the sequences of adaptors and barcodes were removed. Mapping of the sequences was done using Geneious Prime 11.0.5 (www.geneious.com) software. The genome sequences of the wild-type and mutant $S$. Infantis strains were submitted to the GenBank under the access numbers CP040600 and CP040601, respectively.

\section{In vitro adhesion and invasion tests}

Caco-2/An1 (human epithelial colorectal adenocarcinoma) cell culture was used to determine in vitro adhesion and invasion abilities of mutant and wild-type $S$. Infantis strains. Tests were performed as described elsewhere (Giannasca et al. 1996; Salehi et al. 2017). 


\section{Cloning Vector pJETaroA- $\Delta /$ GFP}

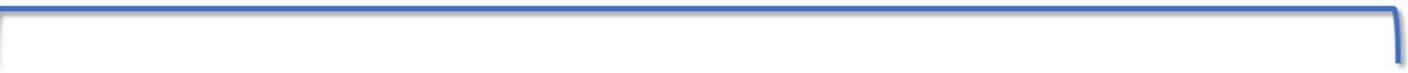

A
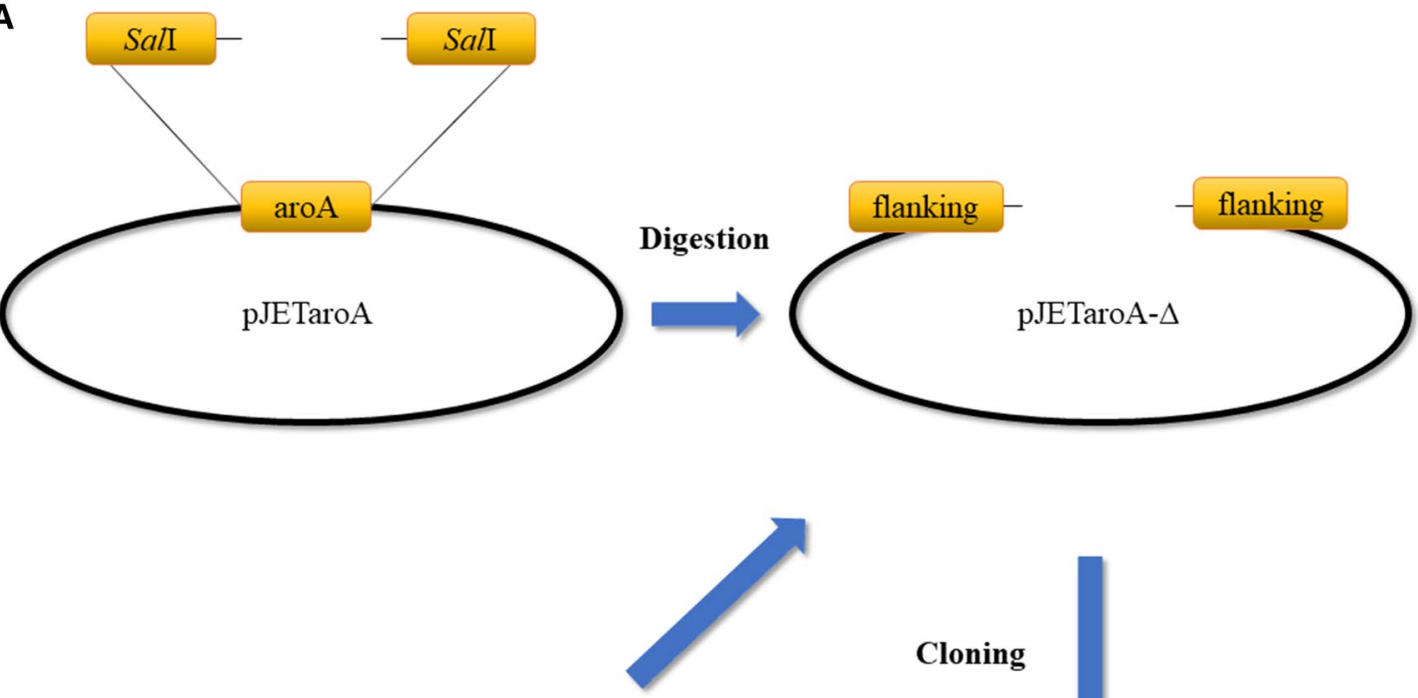

B

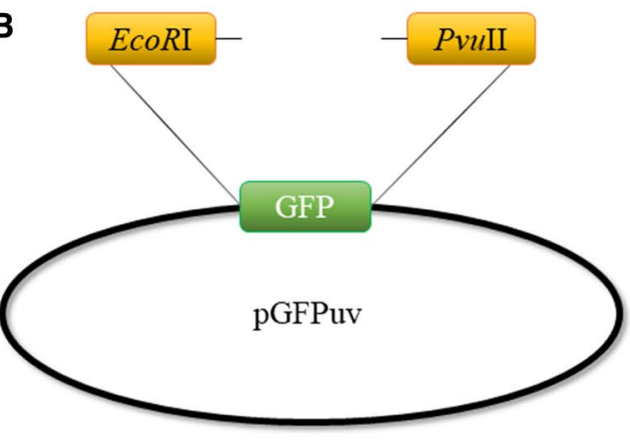

Cloning
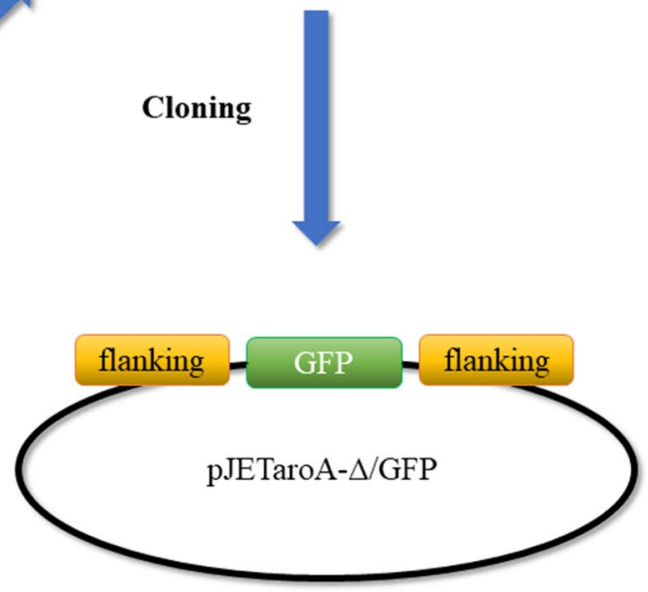

aro $A$-defective $S$. Infantis

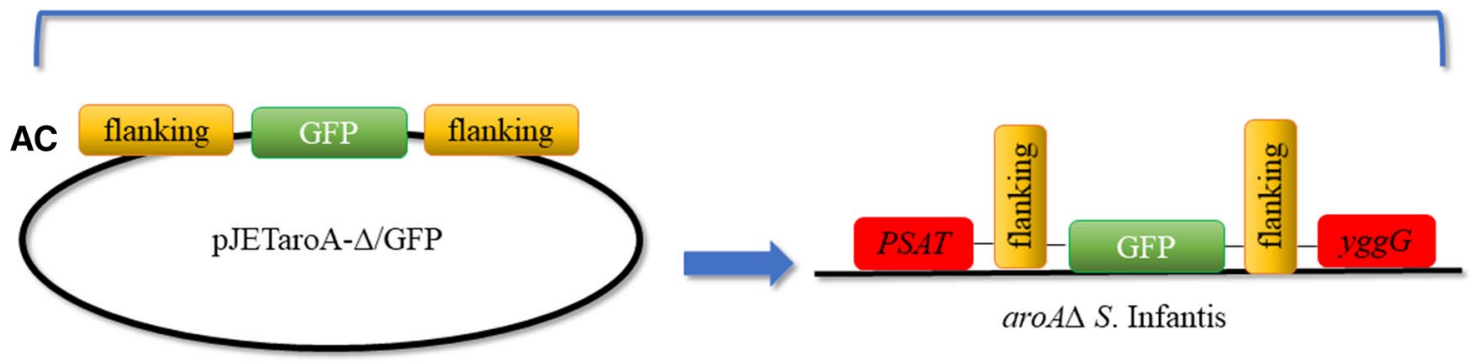

Homologous Recombination

Fig. 1 a, b Schematic figure of constructing cloning vector (pJETaroA- $\Delta /$ GFP), c homologous recombination in wild-type $S$. Infantis strain. $P S A T$ phosphoserine aminotransferase $y g g G$ putative metalloprotease 
Table 2 Antibiotics and their concentrations

\begin{tabular}{ll}
\hline Antibiotic & Concentration \\
\hline Ampisillin (oxoid) & $10 \mu \mathrm{g}$ \\
Gentamycine (oxoid) & $10 \mu \mathrm{g}$ \\
Streptomycine (oxoid) & $10 \mu \mathrm{g}$ \\
Ciprofloxacine (oxoid) & $5 \mu \mathrm{g}$ \\
Nalidixic acide (oxoid) & $30 \mu \mathrm{g}$ \\
Trimethoprime (oxoid) & $5 \mu \mathrm{g}$ \\
Trimethoprim sulfamethoxazole (oxoid) & $300 \mu \mathrm{g}$ \\
Chloramphenicole (oxoid) & $30 \mu \mathrm{g}$ \\
Tetracycline (oxoid) & $30 \mu \mathrm{g}$ \\
Cephotaxime (oxoid) & $5 \mu \mathrm{g}$ \\
\hline
\end{tabular}

\section{Statistical analysis}

Pearson Chi square test was used to evaluate the difference between mutant and wild-type $S$. Infantis strains for rate of adhesion and invasion. Descriptive statistics for each variable were calculated and presented as 'Percentage'. A $P$ value of $<0.05$ was considered statistically significant. All statistical analyses was performed using SPSS 14.01 package program for Windows.

\section{Results and discussion}

Homologous recombination technique was used to produce an aroA-defected $S$. Infantis strain. Homologous recombination is well-designed and straight forward technique if carried out in highly conserved genomic regions. For this approach, up- and downstream flanking sequences (200 bp in length in both sides) were kept around target gene and homologous recombination occurred efficiently. The constructs could be generated in the first attempt by efficiency of $100 \%$ and further confirmed by colony PCR, restriction enzyme analysis and partial sequencing. The final construct (pJETaroA- $\Delta / \mathrm{GFP}$ ) was subsequently transformed into $S$. Infantis and the resulting mutant strain aroA- $\Delta /$ GFP- $S$. Infantis was characterised by PCR and WB at the first step. PCR attempts with MaroA primers revealed 1400 bp product in mutant $S$. Infantis while producing approximately $3000 \mathrm{bp}$ amplicon in wild-type strain. In addition, GFP expression was shown by using WB in mutant $S$. Infantis before and after plasmid elimination. As clearly can be seen in Fig. 2, GFP expression was remarkably exist in $S$. Infantis transformed with pJETaroA- $\Delta$ /GFP. On the other hand, GFP expression did not occur in plasmid eliminated recombinant and wild-type $S$. Infantis strains.

In vitro assays: it was determined that there was no difference in the phenotypic characteristics of recombinant bacteria and wild-type $S$. Infantis, $S$. Enteritidis and $S$.
Fig. 2 Western blot analysis of plasmid-eliminated $S$. Infantis strain (lane 1), Wild-type $S$. Infantis strain (lane 2) and $S$. Infantis strain including plasmid (lane 3) was performed. After transfer of bacterial proteins to PVDF membrane, anti-GFP polyclonal antibody (from rabbit) at dilution of 1:2000 was added and incubated for $1 \mathrm{~h}$ at room temperature followed by three wash steps and incubation with secondary antibody of anti-rabbit IgG-HRPO (whole molecule) antibody (Sigma, USA) at dilution of 1:5000. We added ECL (BioRad, USA) and imaged using Chemi Doc MP System from BioRad (USA). The positive band of about $30 \mathrm{kDa}$ was detected in the Plasmid-eliminated $S$. Infantis strain (lane 1) and $S$. Infantis strain including plasmid (lane 3)

Typhimurium strains. It was determined that the results of biochemical test analysis and culture properties were the same in all strains. Growth curves of the strains at $37^{\circ} \mathrm{C}$ (Fig. 3) and $56^{\circ} \mathrm{C}$ (Fig. 4) revealed no difference among the strains used. Similarly, mutant and wild-type strains showed same movement characteristics based on growth curve patterns in the semi-solid medium. The mutant $S$. Infantis strain was grown on M9 minimal medium supplemented with three amino acids, but not only M9 minimal medium.

Wild-type and aroA-defective $S$. Infantis strains showed varied resistance to antibiotics. Recombinant bacterium became sensitive to nalidixic acid, tetracycline, trimethoprim, and its susceptibility increased against ciprofloxacin, chloramphenicol, ampicillin and streptomycin (Table 3). The recombinant strain was found to be approximately eight times more susceptible to EDTA than wild-type strain according to the MIC values.

According to the PFGE genotypic analysis, it was determined that the gene profiles of the $\operatorname{aro} A \Delta S$. Infantis strain and the wild-type strain were different from each other. As a result of dendrogram analysis based on the similarity matrix obtained by UPGMA analysis, the mutated strain and wild-type $S$. Infantis strains were in different taxas 
Fig. 3 Growth curves of the strains at $37^{\circ} \mathrm{C}$
Growth Curve

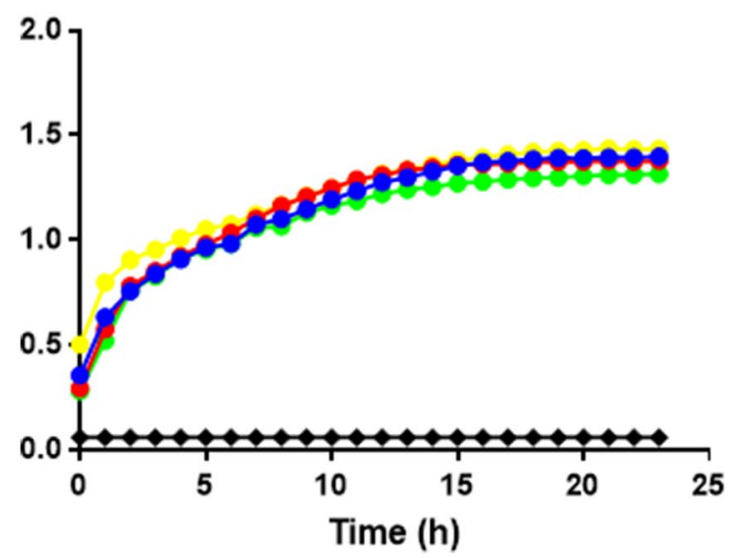

\section{Growth Curve}

strains at $56^{\circ} \mathrm{C}$

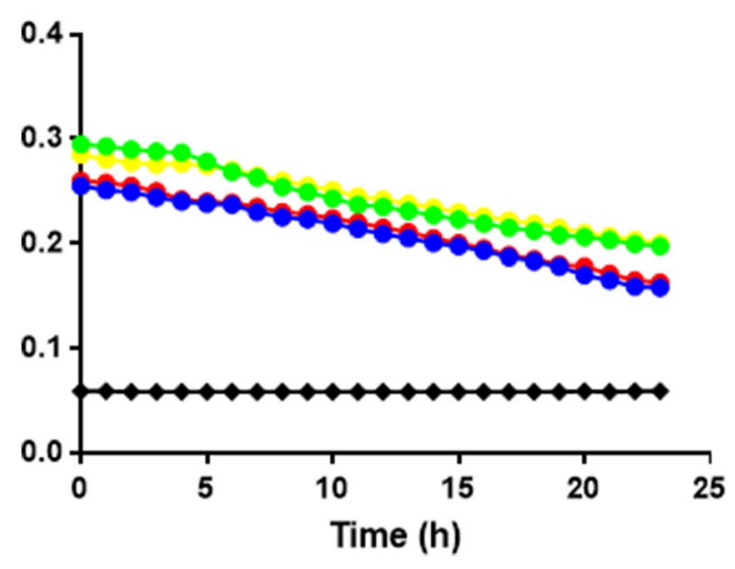

\begin{tabular}{lllllllllll}
\hline Antibiotic disc/zone (mm) & NA & TE & AMP & W & CTX & C & RL & CN & S & CIP \\
\hline Recombinant strain & 23 & 15 & 18 & 29 & 33 & 33 & 0 & 22 & 16 & 30 \\
Wild-type strain & 0 & 0 & 9 & 0 & 33 & 20 & 0 & 20 & 10 & 20
\end{tabular}

$N A$ nalidixicacid, $T E$ tetracycline, $A M P$ ampicillin, $W$ trimethoprim, $C T X$ cefotaxime, $C$ chloramphenicol, $R L$ sulfamethoxazole, $C N$ gentamycin, $S$ streptomycin, $C I P$ ciprofloxacin
Table 3 Comparison of antibiotic disc diffusion test results of $\operatorname{aro} A \Delta$ and wild-type $S$. Infantis strains of wild-type and mutant strains exhibited no difference except this region.

The in vitro adhesion and invasion studies resulted in a mutant strain adhesion rate of $0.07 \%$; invasion rate was $0.03 \%$, while the rate of wild-type strain adhesion was $0.77 \%$; invasion rate was found to be $0.4 \%$. These results indicate that mutant strains have 10 times less invasion and adhesion ability than wild-type strain $(p<0.001)$.

Since the 1980s, mutants lacking aromatic amino acids have been studied in many different species of bacteria, but not in $S$. Infantis strains. Therefore, designing the auxotrophic mutant of a $S$. Infantis strain is performed for the first time. 
Fig. 5 Dendongram analysis of strains. $A M P$ the strain without plasmid elimination, $R E C$ $\operatorname{aro} A \Delta S$. Infantis strain, $S T S$. Typhimurium, $S E S$. Enteritidis, $W T$ wild-type $S$. Infantis strain

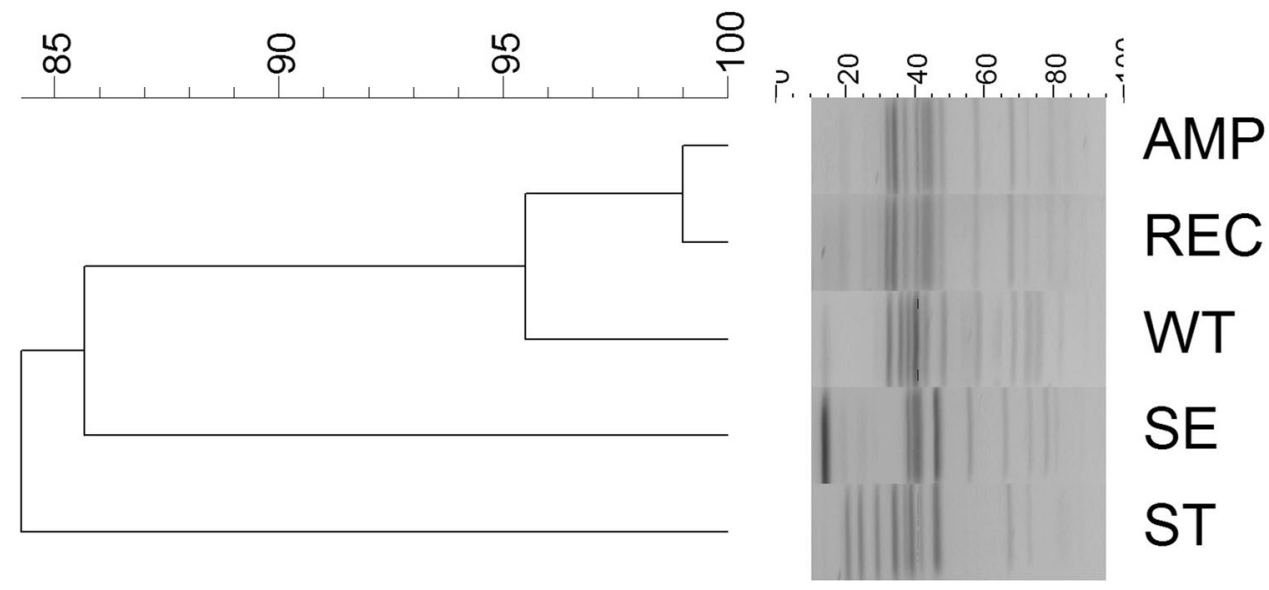

Cooper et al. (1994a) reported that the $\operatorname{aro} A \Delta S$. Enteritidis strain could not form $\mathrm{H}_{2} \mathrm{~S}$ in triple sugar iron (TSI) medium. On the contrary, in the aro $A$ mutant $S$. Infantis strain generated in this study, $\mathrm{H}_{2} \mathrm{~S}$ formation was observed in TSI medium. Cooper et al. (1994a) associate the $\mathrm{H}_{2} \mathrm{~S}$ formation with the aroA mutation, but more detailed studies on this issue are needed.

O'Callaghan et al. (1988) reported that aroA mutant Salmonella strains were able to grow as wild-type strains by providing essential amino acids from the medium. Compatible to this study, it was determined that there was no difference between the strains when the growth curves of the strains were examined at $37^{\circ} \mathrm{C}$ and $56{ }^{\circ} \mathrm{C}$ for $24 \mathrm{~h}$ in the present study.

Sebkova et al. (2008) reported that the susceptibility of aro mutants of some serotypes of $S$. enterica to substances known to be antimicrobial effects such as serum, albumin, EDTA, cysteine, trypsin, lysozyme increased. Sebkova et al. (2008), suggested that this increased sensitivity was due to the deterioration of cell membrane structure in aro mutants. In this study, when EDTA susceptibility known to affect cell membrane was examined, it was determined that the susceptibility to EDTA increased by eight times when comparing mutant strain to wild-type strain. This result supports the results of Sebkova et al. (2008).

Compared to the antibiotic resistance profile, mutant strains were found to be more susceptible or completely susceptible to some antibiotics compared to wild-type strains. It was observed that susceptibilities to aminoglycoside (streptomycin), chloramphenicol, second-generation quinolones (ciprofloxacin) and ampicillin were increased while first-generation quinolones (nalidixic acid), tetracyclin and trimethoprim were found to be completely susceptible. Felgner et al. (2016) reported an increased susceptibility to ampicillin of aroA mutant $S$. Typhimurium strain. The researchers thought that this sensitivity to ampicillin could be due to the deterioration of the outer membrane structure in the aroA mutant $S$. Typhimurium strain. In the present study, the increase in the susceptibility to ampicillin of aroA mutant $S$. Infantis strain supported the result of Felgner et al. (2016). Mutant strain's sensitivity against trimethoprim is consistent with the mechanism of action of trimethoprim and $\operatorname{aro} A$ mutation. It is known that trimethoprim works as PABA antagonist. aroA is a gene necessary for PABA synthesis and it is thought that this mutation prevents PABA synthesis (Smith and Powell 2000). Similarly, it was thought that since PABA synthesis did not occur in aroA $\Delta$. Infantis strain generated in the study, the strain became sensitive to trimethoprim.

It is known that some bacteria require ubiquinone for the flagella production (Hertz and Bar-Tana 1977). Among these bacteria $S$. Typhimurium require the synthesis of ubiquinone, in the presence of aliphatic or aromatic carboxylic acids, for its bacterial growth and flagella production (Bar-Tana et al. 1980). Besides, Sebkova et al. (2008) reported that movement in aro mutants was impaired. In this study, motility test was carried out for the purpose of the control of synthesis of the ubiquinone, one of the end products of the same pathway as the result of extinguishing the aroA gene involved in shikimate pathway, in the $\operatorname{aro} A \Delta S$. Infantis strain. However, the results showed that there was no difference between the recombinant strain and the wild-type strain in terms of movement characteristics. This result suggests that there may be a different mechanism in $S$. Infantis strains for regulation of flagella production.

There are studies for the constitution of aroA mutant recombinant $S$. Enteritidis and $S$. Typhimurium strains in the literature; however, there is no such kind of research for $S$. Infantis, currently the most frequent Salmonella serotype isolated from poultry. This is the first study that aimed to constitute an aroA mutant $S$. Infantis as a vaccine candidate. It was determined that the $\operatorname{aro} A \Delta S$. Infantis strain produced in this study has susceptibility to some antibiotics and also has decreased adhesion and invasion abilities in comparison to the wild strain. 
According to these results, it can be concluded that this recombinant strain can be used as a vaccine candidate in vaccine development research after performing further in vivo investigations on experimental animals.

Acknowledgements We are grateful to Aykut Ozkul for helpful advice during this study and preparation of manuscript. We thank Touraj Aligholipour Farzani and Ali Reza Hanifehnezhad for their valuable guidance, suggestions and help; Ufuk Kaya for statistical analysis. This study was supported by Ankara University Coordinator ship of Scientific Research Projects, under the Project Number 16L0239005. Summarized from the $\mathrm{PhD}$ dissertation of the first author.

Funding This study was funded by Ankara University Coordinator ship of Scientific Research Projects (Grant Number 16L0239005).

\section{Compliance with ethical standards}

Conflict of interest The authors declare that they have no conflict of interest.

Research involving human participants and/or animals This article does not contain any studies with human participants or animals performed by any of the authors.

\section{References}

Antunes P, Mourao J, Campos J, Peixe L (2016) Salmonellosis: the role of poultry meat. Clin Microbiol Infect 22(2):110-121

Barrow PA, Jones MA, Thomson N (2010) Pathogenesis of bacterial infections in Animals. In: Gyles CL, Prescott JF, Songer G, Thoen CO (eds) Salmonella, 4th edn. Arnes, Iowa, USA, pp 231-267

Bar-Tana J, Howlett BJ, Hertz R (1980) Ubiquinone synthetic pathway in flagellation of Salmonella Typhimurium. J Bacteriol 143(2):637-643

Carlton BC, Brown BJ (1981) Gene mutation. In: Gerhardt P, Murray RGE, Costilow RN, Nester EW, Wood WA, Krieg NR, Phillips GB (eds) Manual of methods for general bacteriology, American Society for Microbiology. Washington, DC, USA

CDC (2018) https://www.cdc.gov/pulsenet/pdf/ecoli-shigella-salmo nella-pfge-protocol-508c.pdf. Accessed 02 Oct 2018

Cooper GL, Venables LM, Woodward MJ, Hormaeche CE (1994a) Invasiveness and persistence of Salmonella enteritidis, Salmonella typhimurium, and a genetically defined Salmonella-enteritidis Aroa strain in young chickens. Infect Immun 62(11):4739-4746

Cooper GL, Venables LM, Woodward MJ, Hormaeche CE (1994b) Vaccination of chickens with strain CVL30, a genetically defined Salmonella enteritidis aroA live oral vaccine candidate. Infect Immun 62(11):4747-4754

EUCAST (2014) Development of the EUCAST disk diffusion antimicrobial susceptibility testing method and its implementation in routine microbiology laboratories. Clin Microbiol Infect 20:0255-266

Everest P, Ketley J, Hardy S, Douce G, Khan S, Shea J, Holden D, Maskell D, Dougan G (1999) Evaluation of Salmonella Typhimurium mutants in a model of experimental gastroenteritis. Infect Immun 67(6):2815-2821

Felgner S, Frahm M, Kocijancic D, Rohde M, Eckweiler D, Bielecka A, Bueno E, Cava F, Abraham WR, Curtiss R III, Haussler S, Erhardt M, Weiss S (2016) aroA-Deficient Salmonella enterica serovar typhimurium is more than a metabolically attenuated mutant. Mbio 7(5):e01220-16. https://doi.org/10.1128/mBio.01220-16
Garside LH, Collins M, Langford PR, Rycroft AN (2002) Actinobacillus pleuropneumoniae serotype 1 carrying the defined aroA mutation is fully avirulent in the pig. Res Vet Sci 72(2):163-167

Giannasca KT, Giannasca PJ, Neutra MR (1996) Adherence of Salmonella typhimurium to caco- 2 cells: identification of a glycoconjugate receptor. Infect Immun 64(1):135-145

Hertz R, Bar-Tana J (1977) Anaerobic electron transport in anaerobic flagellum formation in Escherichia coli. J Bacteriol 132(3):1034-1035

Hoiseth SK, Stocker BAD (1981) Aromatic-Dependent Salmonella typhimurium are non-virulent and effective as live vaccines. Nature 291(5812):238-239

McArthur JD, West NP, Cole JN, Jungnitz H, Guzman CA, Chin J Lehrbach PR, Djordjevic SP, Walker MJ (2003) An aromatic amino acid auxotrophic mutant of Bordetella bronchiseptica is attenuated and immunogenic in a mouse model of infection. FEMS Microbiol Lett 221(1):7-16

Miller TPR, Rabsch W, Fehlhaber K, Voss M (2010) Epidemiological relationship between Salmonella Infantis isolates of human and broiler origin. Lohmann Inf 45(2):27

O'callaghan D, Maskell D, Liew FY, Easmon CSF, Dougan G (1988) Characterization of aromatic-dependent and purine-dependent Salmonella typhimurium - attenuation, persistence, and ability to induce protective immunity in Balb/C mice. Infect Immun 56(2):419-423

Robertsson JA, Lindberg AA, Hoiseth S, Stocker B (1983) Salmonella typhimurium infection in calves-protection and survival of virulent challenge bacteria after immunization with live or inactivated vaccines. Infect Immun 41(2):742-750

Salehi S, Howe K, Lawrence Ml, Brooks JP, Bailey RH, Karsi A (2017) Salmonella enterica serovar kentucky flagella are required for broiler skin adhesion and caco-2 cell invasion. Appl Environ Microbiol 83(2):e02115-16. https://doi.org/10.1128/AEM.02115 $-16$

Sambrook J, Russell DW (2001) Molecular cloning: a laboratory manual, vol 3, 3rd edn. Cold Spring Harbor, Laboratory press, New York

Sebkova A, Karasova D, Crhanova M, Budinska E, Rychlik I (2008) aro mutations in Salmonella enterica cause defects in cell wall and outer membrane integrity. J Bacteriol 190(9):3155-3160

Smith CL, Powell KR (2000) Review of the sulfonamides and trimethoprim. Pediatr Rev 21(11):368-371

Tacket CO, Sztein MB, Losonsky GA, Wasserman SS, Nataro JP, Edelman R, Pickard D, Dougan G, Chatfield SN, Levine MM (1997) Safety of live oral Salmonella Typhi vaccine strains with deletions in $h t r A$ and aroC aroD and immune response in humans. Infect Immun 65(2):452-456

Tacket CO, Sztein MB, Wasserman SS, Losonsky G, Kotloff KL, Wyant TL, Natoro JP, Edelman R, Perry J, Bedford P, Brown D, Chatfield S, Dougan G, Levine MM (2000) Phase 2 clinical trial of attenuated Salmonella enterica serovar Typhi oral live vector vaccine CVD 908-htrA in U.S. volunteers. Infect Immun 68(3):1196-1201

Tittsler RP, Sandholzer LA (1936) The use of semi-solid agar for the detection of bacterial motility. J Bacteriol 31(6):575-580

Grimont PAD, Weill FX (2007) Antigenic Formulae of the Salmonella Serovars. In: World Health Organization Collaborating Center forReference and Research on Salmonella, 9th edn. Institut Pasteur, Paris.

Publisher's Note Springer Nature remains neutral with regard to jurisdictional claims in published maps and institutional affiliations. 